for portions of the repair (ie, annuloplasties and tightening of neochordae).

Complete absence of chordal structures associated with leaflet prolapse, such as seen with a cleft in the anterior mitral leaflet, creates a difficult problem for short- and longterm outcomes in pediatric patients. Routine maneuvers such as commissuroplasties and annuloplasties are not always effective. More complex techniques including creating neochordae ${ }^{3}$ or creating a double-orifice mitral valve (ie, the Alfieri repair ${ }^{6}$ ) can often provide effective short-term results. Alfieri's initial description ${ }^{6}$ of edge-to-edge leaflet approximation for adults with severe regurgitation has proven excellent results and should be considered in children. However, the creation of neochordae $e^{3,4}$ for significant prolapse provides a more natural effect and less potential for mitral stenosis; if necessary, as the child grows, the neochordae can be replaced without valve replacement.

Using preoperative and intraoperative 3- and 2-dimensional echocardiography, one is able to optimally plan an approach and the repair of complicated mitral valve abnormalities. Furthermore, as an alternative to complete cardioplegic arrest, spontaneously induced hypothermic ventricular fibrillation allows one to inspect and perform much of the repair under more physiologic conditions without significantly compromising myocardial function.

I would like to thank Dr Pedro del Nido for his continuing contributions to the field of congenital valve disease and repair. Dr del Nido at Boston Children's Hospital developed many of the concepts used herein, passing them to me during my time in Boston. I would also like to thank Heather Claremont for help with the illustrations.

\section{References}

1. Shone JD, Sellers RD, Anderson RC, Adams P Jr, Lillehei CW, Edwards JE. The developmental complex of "parachute mitral valve," supravalvular ring of left atrium, subaortic stenosis, and coarctation of aorta. Am J Cardiol. 1963;11: 714-25.

2. Carpentier A, Branchini B, Cour JC, Asfaou E, Villani M, Deloche A, et al. Congenital malformations of the mitral valve in children: pathology and surgical treatment. J Thorac Cardiovasc Surg. 1976;72:854-66.

3. Duran CM, Pekar F. Techniques for ensuring the correct length of new mitral chords. J Heart Valve Dis. 2003;12:156-61.

4. Boon R, Hazekamp M, Hoohenkerk G, Rijlaarsdam M, Schoof P, Koolbergen D et al. Artificial chordae for pediatric mitral and tricuspid valve repair. Eur J Cardiothorac Surg. 2007;32:143-8.

5. Cannon JW, Stoll JA, Salgo IS, Knowles HB, Howe RD, Dupont PE, et al. Realtime three-dimensional ultrasound for guiding surgical tasks. Comput Aided Surg. 2003;8:82-90

6. Fucci C, Sandrelli L, Pardini A, Torracca L, Ferrari M, Alfieri O. Improved results with mitral valve repair using new surgical techniques. Eur J Cardiothorac Surg. 1995;9:621-6; discussion 626-7.

\title{
Iatrogenic phrenic nerve injury during thymectomy: The extent of the problem
}

\author{
Michele Salati, MD, ${ }^{\mathrm{a}}$ Giuseppe Cardillo, MD, FETCS, ${ }^{\mathrm{b}}$ Luigi Carbone, MD, ${ }^{\mathrm{b}}$ Federico Rea, MD, ${ }^{\mathrm{c}}$ \\ Giuseppe Marulli, MD, ${ }^{\mathrm{c}}$ Alessandro Brunelli, MD, ${ }^{\mathrm{a}}$ Luca Voltolini, MD, ${ }^{\mathrm{d}}$ Giuseppe Gotti, MD, ${ }^{\mathrm{d}}$ and \\ Gaetano Rocco, MD, FRCSEd, ${ }^{\mathrm{e}}$ Ancona, Rome, Padua, Siena, and Naples, Italy
}

If a thymic neoplasm infiltrates both the phrenic nerves, it is mandatory to spare one of them to reduce respiratory function impairment. ${ }^{1}$ To our knowledge, there is no information in the

\footnotetext{
From the Unit of Thoracic Surgery, ${ }^{a}$ Umberto I Regional Hospital, Ancona, Italy; the Unit of Thoracic Surgery, ${ }^{b}$ Azienda Ospedaliera San Camillo Forlanini, Rome, Italy; the Department of Cardiologic, Thoracic and Vascular Sciences, Division of Thoracic Surgery, ${ }^{c}$ University of Padova, Padua, Italy; the Thoracic Surgery Unit, ${ }^{\mathrm{d}}$ University Hospital of Siena, Siena, Italy; and the National Cancer Institute, ${ }^{\mathrm{e}}$ Pascale Foundation, Naples, Italy.

Disclosures: None.

Received for publication April 23, 2008; revisions received May 20, 2008; accepted for publication June 10, 2008; available ahead of print June 1, 2009.

Address for reprints: Michele Salati, MD, Via A. De Gasperi 17/c, 60020 Offagna, Italy (E-mail: michelesalati@hotmail.com).

J Thorac Cardiovasc Surg 2010;139:e77-8

$0022-5223 / \$ 36.00$

Copyright (C) 2010 by The American Association for Thoracic Surgery

doi:10.1016/j.jtcvs.2008.06.051
}

literature regarding the incidence of unilateral phrenic nerve resection for radically treated thymic neoplasms (Figure 1).

\section{CLINICAL SUMMARY}

In January 2007 we created a multi-institutional diseasespecific database. We retrospectively gathered data in an electronic format from 5 Italian thoracic surgery units, each of them performing at least 8 thymectomies per year, irrespective of the surgical approach.

We enrolled 183 patients ( 93 female and 90 male patients; median age, 56.6 years) from January 2000 to December 2006 who were operated on for thymoma or thymic carcinoma. Patients with a preoperative diagnosis of generalized myasthenia or other neuromuscular syndromes were excluded.

Two of the following criteria should be verified to define the phrenic nerve as injured after the operation: (1) description of the phrenic nerve resection within the operating 


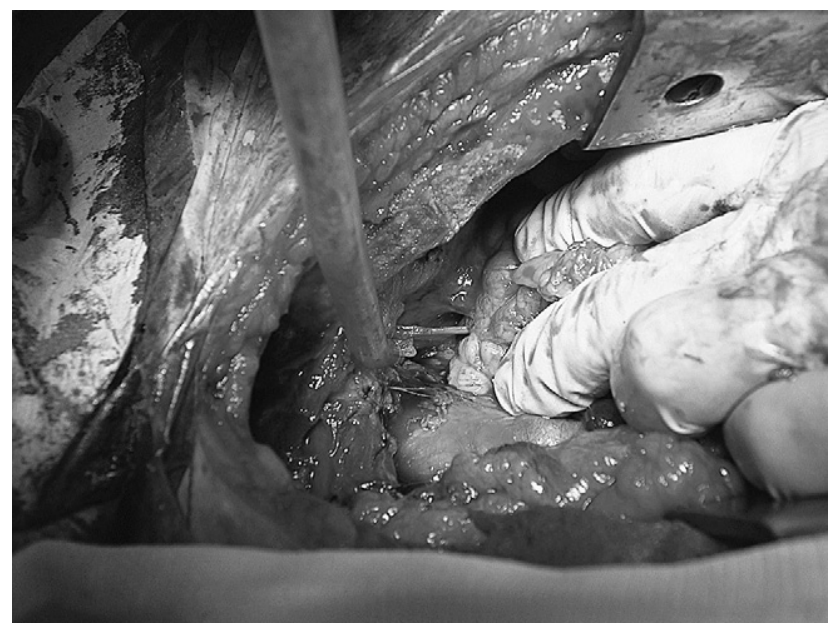

FIGURE 1. Thymic neoplasm infiltrating the phrenic nerve.

report, (2) description of a phrenic nerve segment detected during the pathologic examination, and (3) postoperative chest radiographic finding of an elevated hemidiaphragm (in patients without this finding in the preoperative chest radiograph).

Table 1 summarizes histopathologic diagnosis, stage, surgical approach of the patients in analysis, and incidence of phrenic nerve injuries in each stage.

Of the 183 patients, 13 met the criteria to be considered affected by a surgical injury of the phrenic nerve. This means that in our experience to achieve a radical resection of the thymic tumor in our patients, we had to sacrifice the phrenic nerve in about $7 \%$ of them. The postoperative cardiopulmonary morbidity rate was $7 \%$ without mortality.

\section{DISCUSSION}

Surgical intervention has always been considered a fundamental tool to treat tumors of the thymus gland., ${ }^{2,3}$ Used alone or integrated in a multimodality approach, the surgical treatment should lead to a radical resection of the tumor also in those cases in which it invades the lung, pleura, diaphragm, vascular structures (superior vena cava and brachiocephalic vein), pericardium, or phrenic nerve. ${ }^{4,5}$ This study was designed primarily to assess the incidence of phrenic nerve resection during thymectomy. Further analyses are
TABLE 1. Patients' classification and incidence of phrenic nerve injury by stage of thymoma

\begin{tabular}{clcc}
\hline Categories & $\begin{array}{c}\text { Patients, } \\
\text { no. }(\%))^{*}\end{array}$ & $\begin{array}{c}\text { Resected phrenic } \\
\text { nerve, no. }(\%) \dagger\end{array}$ \\
\hline Histology & Thymoma A & $22(12 \%)$ & $2(9 \%)$ \\
WHO & Thymoma AB & $64(35 \%)$ & $3(5 \%)$ \\
& Thymoma B1 & $26(14 \%)$ & $2(8 \%)$ \\
& Thymoma B2 & $33(18 \%)$ & $2(6 \%)$ \\
& Thymoma B3 & $31(17 \%)$ & $3(10 \%)$ \\
& Thymoma C & $7(4 \%)$ & $1(14 \%)$ \\
Masaoka & Stage I & $53(29 \%)$ & $1(2 \%)$ \\
Stage & Stage II & $99(54 \%)$ & $10(10 \%)$ \\
& Stage III & $24(13 \%)$ & $2(8 \%)$ \\
Surgical & Stage IV & $7(4 \%)$ & $0(0)$ \\
approach & Sternotomy & $168(92 \%)$ & \\
& Sternotomy & $1(0.5 \%)$ & \\
& +thoracotomy & & \\
& Thoracotomy & $9(5 \%)$ & \\
& Cervicotomy & $1(0.5 \%)$ & \\
& Robot & $4(2 \%)$ & \\
\hline
\end{tabular}

WHO, World Health Organization. *Percentage calculated based on the total of patients in the study as denominator. †Percentage calculated based on the number of patients per stage as denominator.

needed to ascertain the effect of this lesion on residual respiratory function and quality of life. These will be crucial factors in revising informed consent policies and comparing clinical outcomes. In this setting the next task will be to ascertain phrenic nerve injury-related pulmonary functional loss and collect figures from distributed quality-of-life questionnaires with the aim to provide useful data for patient counseling and medicolegal implications.

\section{References}

1. Block IM. Thymic tumors. In: Pearson GF, Cooper JD, Deslauriers J, Ginsberg RJ, Hiebert CA, Patterson GA, et al., eds. Thoracic surgery. 2nd ed. New York: Churchill Livingstone; 2002. p. 1682-710.

2. Kondo K, Monden Y. Therapy for thymic epithelial tumors: a clinical study of 1,320 patients from Japan. Ann Thorac Surg. 2003;76:878-84.

3. Detterbeck FC, Parsone AM. Thymic tumors. Ann Thorac Surg. 2004;77: 1860-9.

4. Rea F, Marulli G, Girardi R, Bortolotti L, Favaretto A, Galligioni A, et al. Longterm survival and prognostic factors in thymic epithelial tumours. Eur J Cardiothorac Surg. 2004;26:412-8.

5. Johnson SB, Eng TY, Giaccone G, Thomas CR Jr. Thymoma: update for the new millennium. Oncologist. 2001;6:239-46. 